\title{
An experimental study on flexural strength enhancement of concrete by means of small steel fibers
}

\author{
Abdoullah Namdar, Ideris Bin Zakaria, Azimah Bt Hazeli, Sayed Javid Azimi, Abdul Syukor Bin \\ Abd. Razak \\ Department of Civil Engineering \& Earth Resources, Universiti of Malaysia Pahang, Malaysia \\ ab_namdar@yahoo.com
}

G. S. Gopalakrishna

Department of Earth Science, University of Mysore, India

\begin{abstract}
Cost effective improvement of the mechanical performances of structural materials is an important goal in construction industry. To improve the flexural strength of plain concrete so as to reduce construction costs, the addition of fibers to the concrete mixture can be adopted. The addition of small steel fibers with different lengths and proportion have experimentally been analyzed in terms of concrete flexural strength enhancement. The main objectives of the present study are related to the evaluation of the influence of steel fibers design on the increase of concrete flexural characteristics and on the mode of failure. Two types of beams have been investigated. The force level, deflection and time to failure of beams have been measured. The shear crack, flexural crack and intermediate shear-flexural crack have been studied. The steel fiber content controlled crack morphology. Flexural strength and time to failure of fiber reinforce concrete could be further enhanced if, instead of smooth steel fibers, corrugated fibers were used.
\end{abstract}

KEYwords. Steel fiber; Flexural strength; Corrugated steel fiber; Flexibility of beam; Shear crack; Flexural crack.

\section{INTRODUCTION}

7 he fiber reinforcement concrete mix design helps to construct high quality of concrete structure. To improve concrete strength, effect of fiber distribution on flexural strength of ultra-high strength concrete has been investigated. The ultimate flexural strength and time to first crack have been affected [1]. The placing methods control fiber distribution and mechanical performance of short-fiber reinforced concrete [2, 3]. The flexural behavior include cracking, failure pattern, deflection, ductility, and flexural strength have been studied. A prediction model for the flexural strength and deflection of ultra-high strength concrete beams under bending conditions has been proposed [4]. There is an analytical solution for calculation of flexural strength of strengthened composite beams. And experimental results from literature have been employed to validate results of both the analytical and finite element method [5]. A design method has been reported on ultimate strength criteria for small steel fiber reinforced concrete (SFRC) slabs. The slabs under flexure, with longer fibers and higher fiber content provide higher energy absorption [6-7]. The splitting tensile and flexural strengths have largely been improved with increase fiber volume [8]. The ductility of concrete with synthetic fibers has been investigated for analysis flexural stress-deflection [9]. The objectives of this research work are, to investigate effect of small steel fibers on flexural strength of small beam. The length and proportion of steel fibers have been investigated. The deflection, time of stability and crack morphology of the concrete beams have been discussed. 


\section{EXPERIMENTAL SET-UP}

he small steel fiber has been mixed with plain concrete. The beam B1 made with100 mm $\times 100 \mathrm{~mm} \times 500 \mathrm{~mm}$ dimensions. Length of small steel fiber $10 \mathrm{~mm}, 20 \mathrm{~mm}, 30 \mathrm{~mm}, 40 \mathrm{~mm}$ and $50 \mathrm{~mm}$ has been varied. The quantity of small steel fiber $0.5 \%$ and $1 \%$ weight of concrete has been selected (Fig. 1-2).
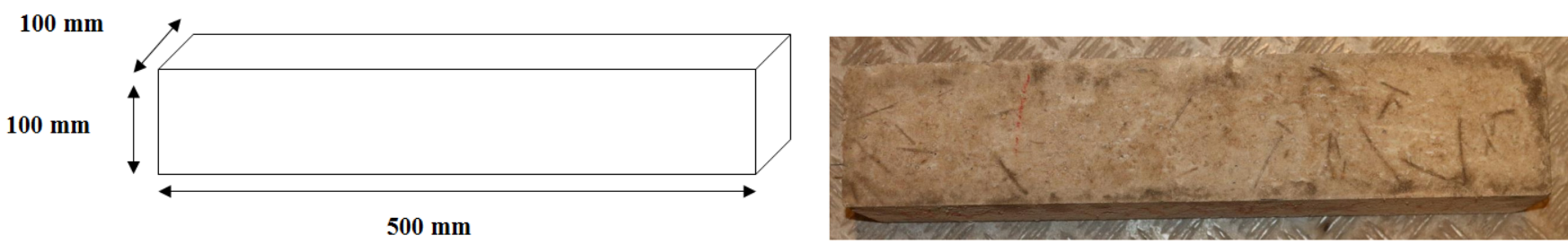

Figure 1: Beam B1, steel fiber shown in surface of beam.

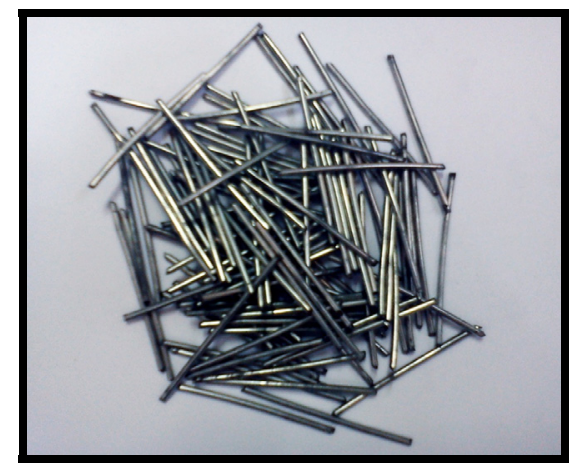

Figure 2: Steel fiber.

\section{PREPARATION PROCEDURE OF SPECIMENS}

$\mathrm{O}$

rdinary Portland Cement (OPC), sand, coarse aggregate and water have been used for casting plain concrete. Small smooth steel fiber of $0.5 \%$ \& $1.0 \%$ has been mixed with plain concrete (Fig. 2-3 and Tab. 1). After curing the flexural strength and crack morphology of concrete beams have been investigated.

The plain concrete cube with dimensions of $100(\mathrm{~mm}) \times 100(\mathrm{~mm}) \times 100(\mathrm{~mm})$ has been made and tested, the results show $28.51\left(\mathrm{~N} / \mathrm{mm}^{2}\right)$ stress and strain of $0.01488 \%$, this is as predicted during the design stage (Fig. 4-5). The plain concrete has been designed for sustain stress of $40\left(\mathrm{~N} / \mathrm{mm}^{2}\right)$ on 28 days. The compressive strength of specimen reached to $70 \%$ of design on 14 days. The result is acceptable according to ACI standard.

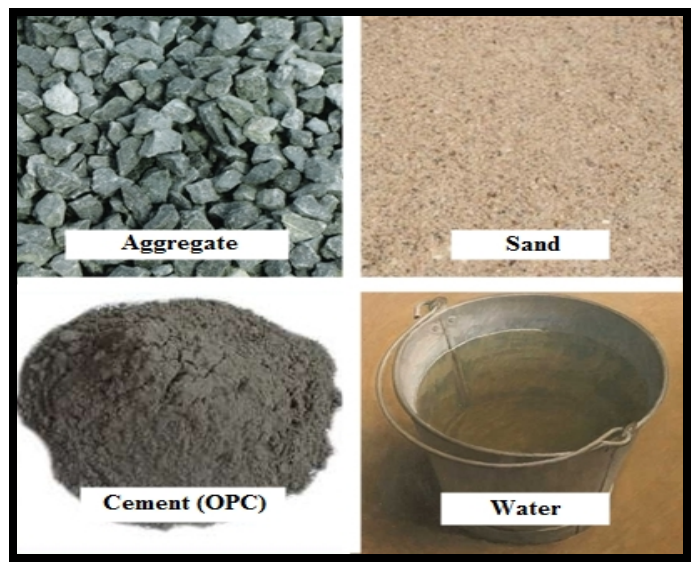

Figure 3: Basic materials of concrete. 


\begin{tabular}{cc}
\hline Ingredients & $\begin{array}{c}\text { Amount }\left(\mathrm{kg} / \mathrm{m}^{3}\right) \\
\text { Grade } 40\end{array}$ \\
W/C Ratio & 0.47 \\
Mix Water & 92.73 \\
Cement (Portland) & 198 \\
Fine Aggregate (Sand) & 320.76 \\
Coarse Aggregate (Max: 20mm) & 593.9 \\
\hline
\end{tabular}

Table 1: Proportion of materials for concrete Grade 40.

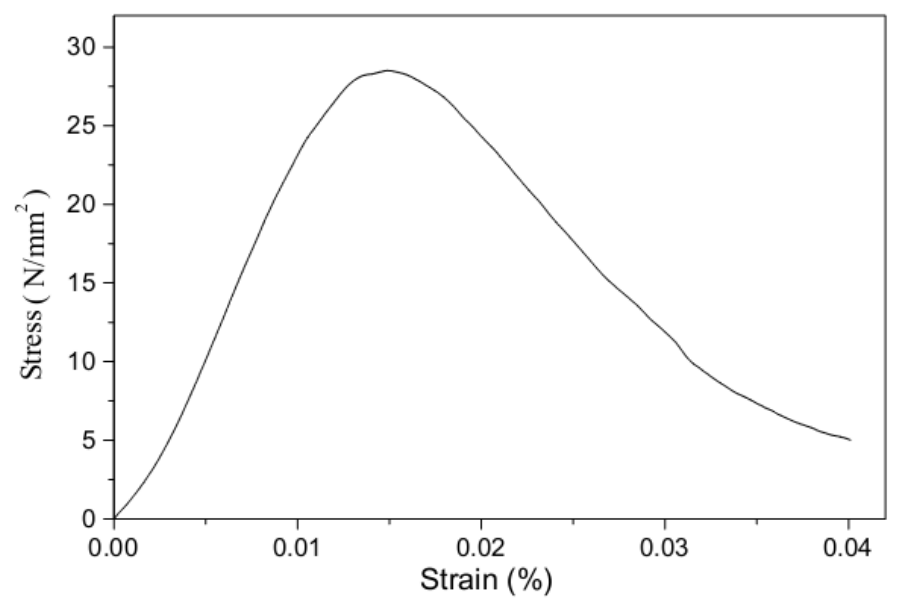

Figure 4: Stress-strain curve of plain concrete on 14 days.
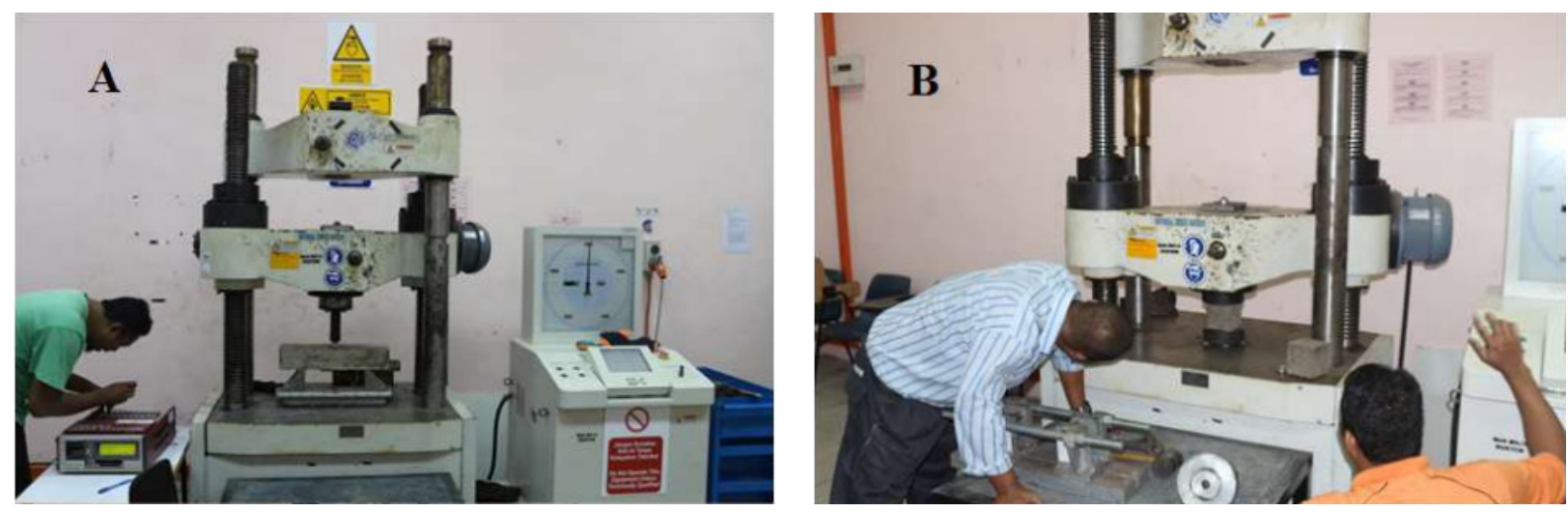

Figure 5: Deflection testing equipment for testing beam B1 (part A) and same equipment used to measured compressive strength of plain concrete cube (part B).

\section{METHOD OF CONCRETE MIXING}

7 he plain concrete has been produced by using conventional method. In order to make good plain concrete, first the water has been dropped in mixer and subsequently cement has been added to the water and mixture has been continued until the cement paste has been made, then all aggregates have uniformly been mixed, and mixer has been stopped. The fiber has been added at final step. The linearly distribution of fiber is critical part of this method. The steel fiber in surface of beam is shown in Fig. 1. Concrete-steel fiber mixture needs to be done carefully to ensure the steel 
fiber has uniformly been distributed. The fiber reinforced concrete has been poured into mould. For vibration of specimens, the vibration Tab. has been used. The specimens have been covered by using wet sack about 24 hours. After 24 hours the concrete beams have been demoulded. The concrete beams have been kept at water $30 \pm 5^{\circ} \mathrm{C}$ for 14 days.

\section{EXPERIMENTAL PROCEDURE}

7 he supporting loading rollers, specimen and bearing surfaces have been cleaned. The specimens have been weighed and marked then placed in the machine in right angle to the rollers. In beam B1 and B2 the strain gauges have been installed on one third of end at each side of beam. The maximum applied force, stroke and time to failure of beams have been recorded by using strain gauges. The load has been applied to beam steadily without shock. The rate of loading has been maintained in constant level until failure of beam. The types of failure mode and crack have been recorded.

\section{RESULTS AND DISCUSSION}

7 he results indicate that the flexure strength of beam B1 (made up with non-fiber reinforcement concrete) is 3.932 $\mathrm{N} / \mathrm{mm}^{2}$. Tab. 2 and Fig. 6 illustrate flexure strength of beam B1 (made up with fiber reinforcement concrete). The results show, for this type of fiber reinforcement concrete beam the best length of steel fiber is $50 \mathrm{~mm}$. The economical proportion of steel fiber is $0.5 \%$. Increase steel fiber length maybe result in better product.

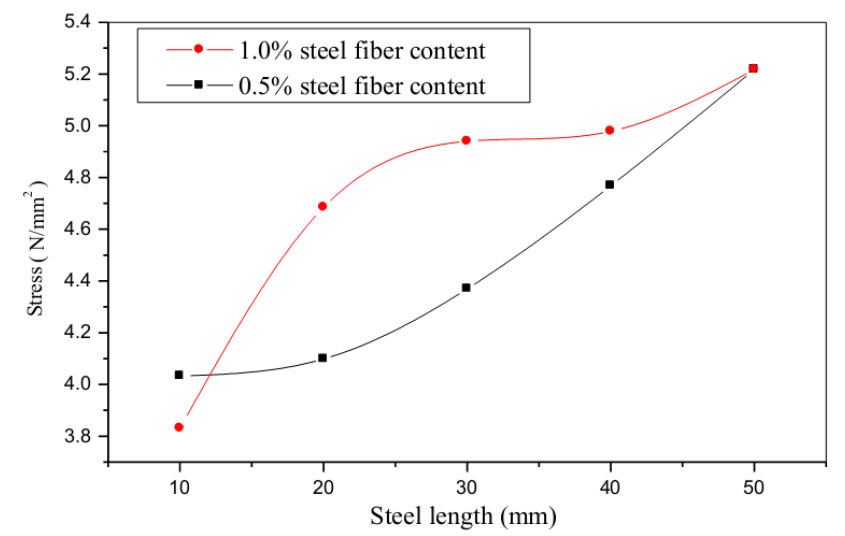

Figure 6: Steel length $(\mathrm{mm})$ vs 14 days stress $\left(\mathrm{N} / \mathrm{mm}^{2}\right)$.

\begin{tabular}{cccc}
\hline S1 & $\begin{array}{c}\text { Length of } \\
\text { fiber }\end{array}$ & $\begin{array}{c}\text { 14 days stress (MPa) } \\
\text { used } 0.5 \% \text { steel } \\
\text { fiber }\end{array}$ & $\begin{array}{c}\text { 14 days stress (MPa) } \\
\text { used 1\% steel fiber }\end{array}$ \\
\hline 1 & 10 & 4.033 & 3.831 \\
2 & 20 & 4.099 & 4.685 \\
3 & 30 & 4.370 & 4.940 \\
4 & 40 & 4.768 & 4.979 \\
5 & 50 & 5.218 & 5.218 \\
\hline
\end{tabular}

Table 2: Flexure strength of reinforced concrete beam

\section{MODE OF FAILURE AND STEEL FIBER MIXTURE DESIGN}

$\mathrm{E}$

ffect of steel fiber on flexural strength, time of stability, failure mode, force applicability, and crack morphology of a concrete beam needs to investigate. In this research work, effect of shape and surface roughness of steel fiber on concrete beam has not been investigated. The second types of beam namely B2 with dimensions of $150(\mathrm{~mm})$ 
$\times 150(\mathrm{~mm}) \times 1000(\mathrm{~mm})$ has been designed. The proportion of steel fiber for beam B1 $0.5 \%$ and $1 \%$, and for beam B2 $1 \%$ of weight of concrete beam have been proposed (Tab. 3).

\begin{tabular}{|c|c|c|c|c|c|c|c|}
\hline \multirow[b]{2}{*}{$\begin{array}{l}\text { Sl. } \\
\text { No }\end{array}$} & \multirow[b]{2}{*}{$\begin{array}{l}\text { L.F } \\
(\mathrm{mm})\end{array}$} & W.F & $\% . F$ & W.F & $\% . F$ & W.F & $\% . F$ \\
\hline & & \multicolumn{2}{|c|}{$\begin{array}{c}\text { Beam B1 content } \\
0.5 \% \text { fiber }\end{array}$} & \multicolumn{2}{|c|}{$\begin{array}{c}\text { Beam B1 content } \\
1 \% \text { fiber }\end{array}$} & \multicolumn{2}{|c|}{$\begin{array}{c}\text { Beam B2 content } \\
1 \% \text { fiber }\end{array}$} \\
\hline 1 & 10 & 4.08 & 6.67 & 8.15 & 6.67 & 20 & 3.64 \\
\hline 2 & 20 & 8.15 & 13.33 & 16.30 & 13.33 & 30 & 5.45 \\
\hline 3 & 30 & 12.23 & 20.00 & 24.45 & 20.00 & 100 & 18.18 \\
\hline 4 & 40 & 16.30 & 26.66 & 32.60 & 26.67 & 150 & 27.27 \\
\hline 5 & 50 & 20.38 & 33.33 & 40.75 & 33.33 & 250 & 45.45 \\
\hline
\end{tabular}

Table 3: Steel fiber mixture design for beam B2.

The Fig. 7 shows strain gauges installed on concrete beam. Strain gauges have been measured applied force on concrete beam, stroke and time of stability of concrete beam. The cracking pattern at failure shows in Fig. 8-9 for beams B1. The beams failed in the flexural-tension mode. If proportion of steel fiber increases to $1 \%$ the type of mode failure depends on harmony distribution of steel fiber. Increases length of steel fiber modifies type of cracking pattern. The type and morphology of cracks have direct relationship with proportion of fiber. Increases quantity of fiber, results in higher stroke before failure and improves time of stability. In beam B1 contents $0.5 \%$ fiber, failure occurs after 83 sec during applied force is $17.24(\mathrm{kN})$ with stroke of $0.67 \mathrm{~mm}$. In beam B1 contents $0.1 \%$ fiber, failure occurs after $196 \mathrm{sec}$ during applied force reaches to $27.67(\mathrm{kN})$ with stroke of $1.61 \mathrm{~mm}$. (Fig. 10-13). The experimental results have been revealed, using $1 \%$ steel fiber better improves flexibility and time of stability of beam B1. The types of graph of force versus stroke and force versus time are depending on steel fiber content. Addition of steel fiber to beam B1 and B2 increases time to crack of beams. The load and deflection curve diagram have been affected by the addition of fibers. The appropriate quantity of steel fiber reduces beam deformation and increases flexural strength of beam. In beam B2 made up from plain concrete, failure occurs after $38 \mathrm{sec}$ during applied force is $27.53(\mathrm{kN})$ with stroke of $0.3 \mathrm{~mm}$. In beam B2 content $1 \%$ small steel fiber, failure occurs after $200 \mathrm{sec}$ during force is $30.59(\mathrm{kN})$ with stroke of $1.64 \mathrm{~mm}$. (Fig. 14-19).

The Fig. 8, 9, 14 and 15 show small steel fibre controls the crack behaviour. The Fig. 14 depicts shear crack on beam B2, (builds up from plain concrete). The Fig. 15 shows flexural crack on beam B2, (builds up from fiber reinforced concrete, content $1 \%$ steel fibre). Content 1\% steel fibre convert shear crack to the flexural crack. The Fig. 8 shows morphology of crack appears between shear crack and flexural crack. This is intermediate shear-flexural crack propagation. This method has good agreement for mitigate of beam shear failure.

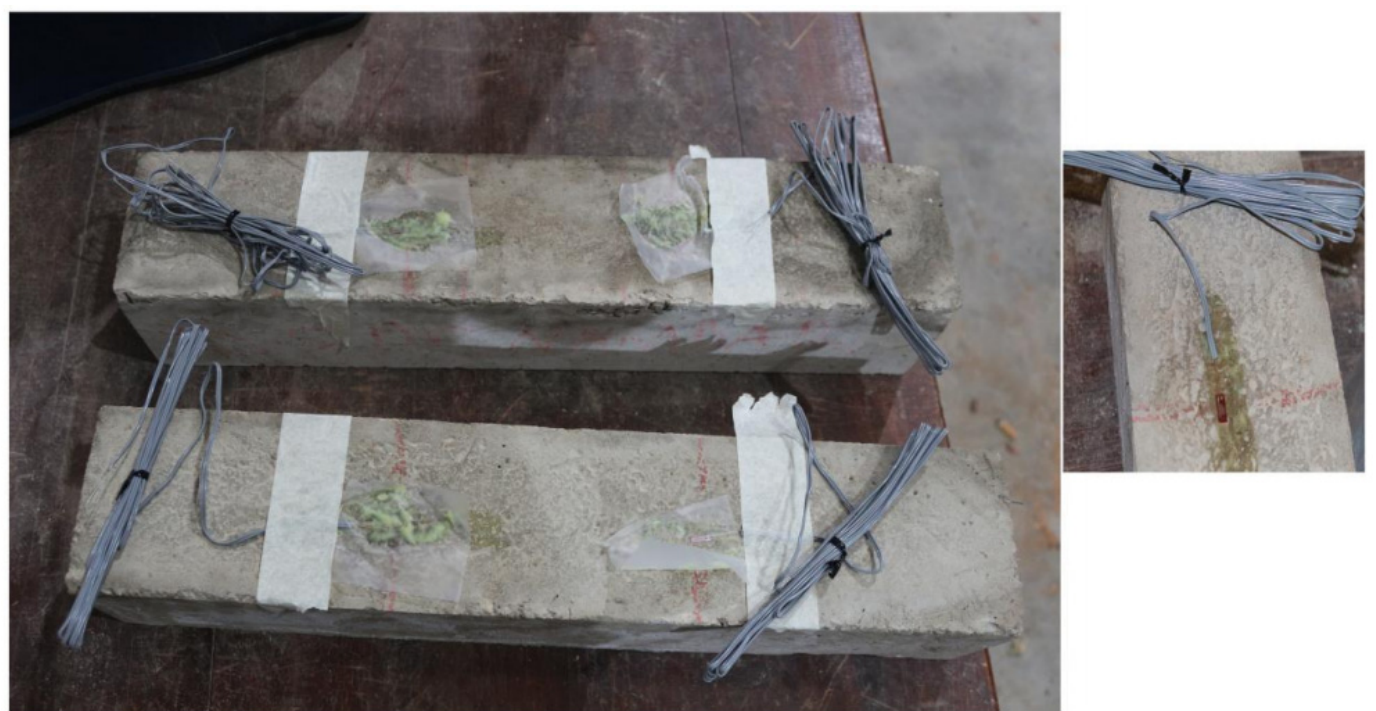

Figure 7: Strain gauges installed on concrete beam. 


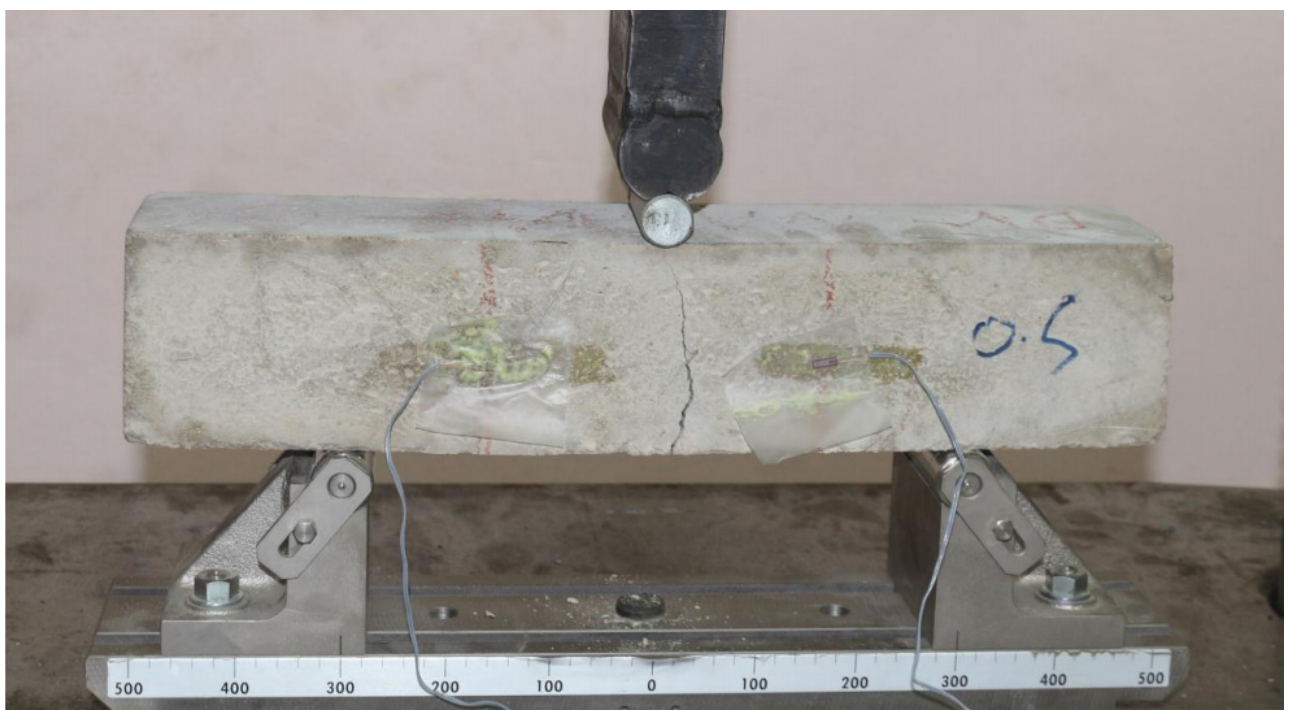

Figure 8: Failure mode for beam B1, content $0.5 \%$ steel fibers.

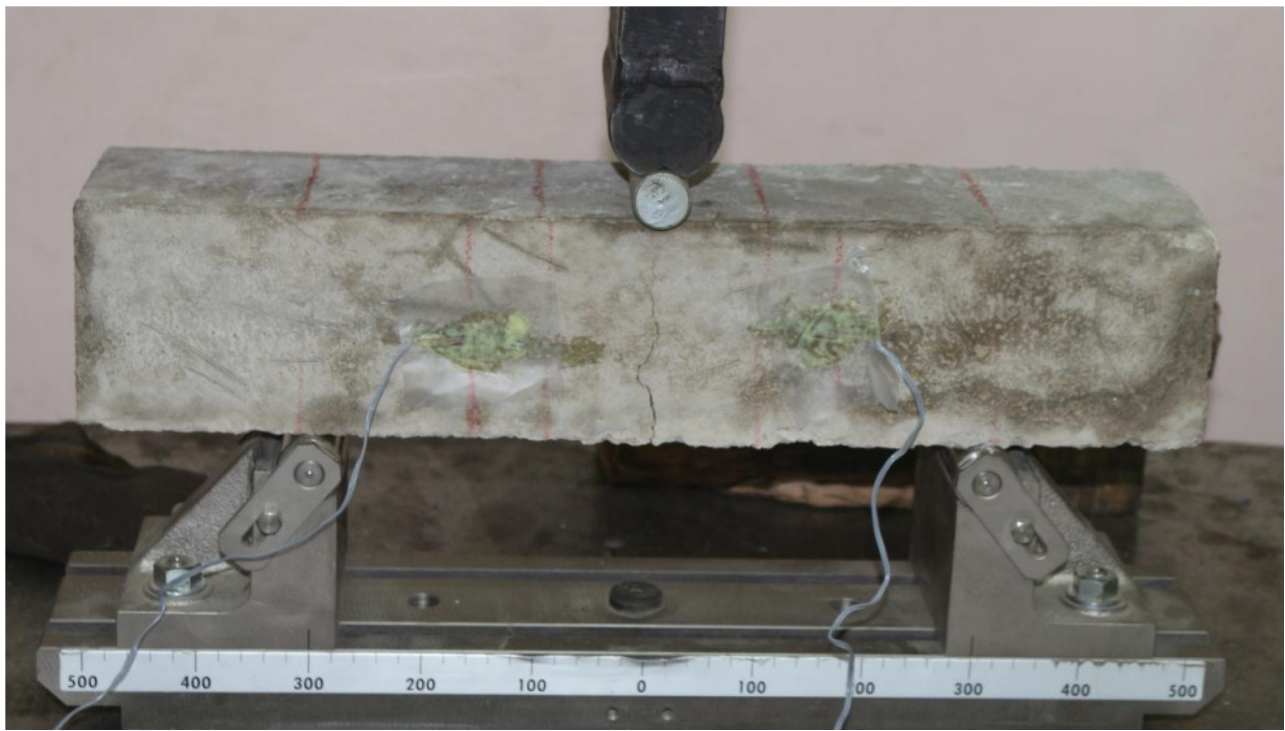

Figure 9: Failure mode for beam B1, content 1.0\% steel fibers.

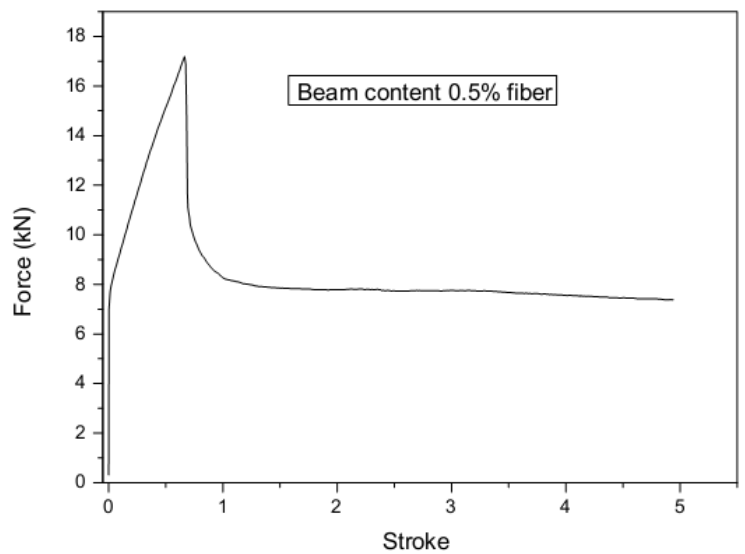

Figure 10: Force vs stroke in beam B1, content $0.5 \%$ steel fibers.

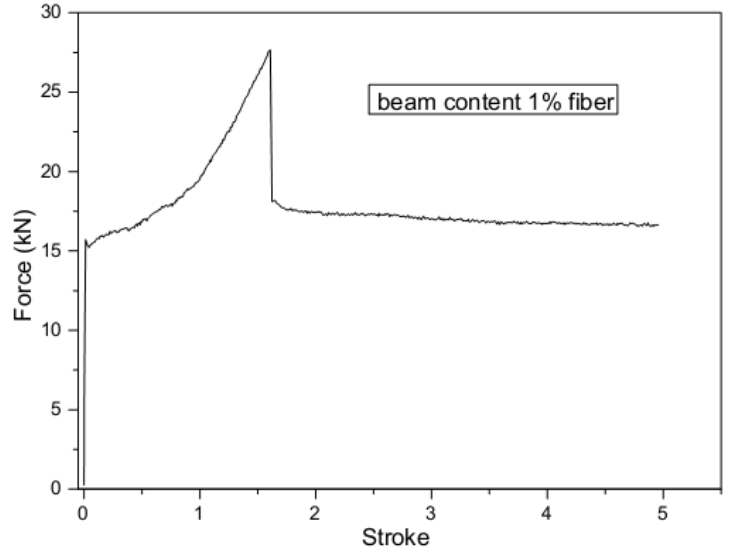

Figure 11: Force vs stroke in beam B1, content 1\% steel fibers. 


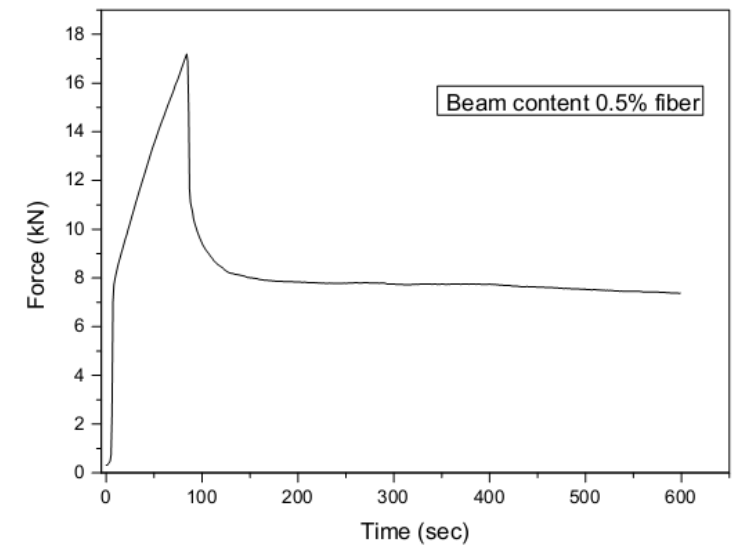

Figure 12: Force vs time in beam B1, content $0.5 \%$ steel fibers.

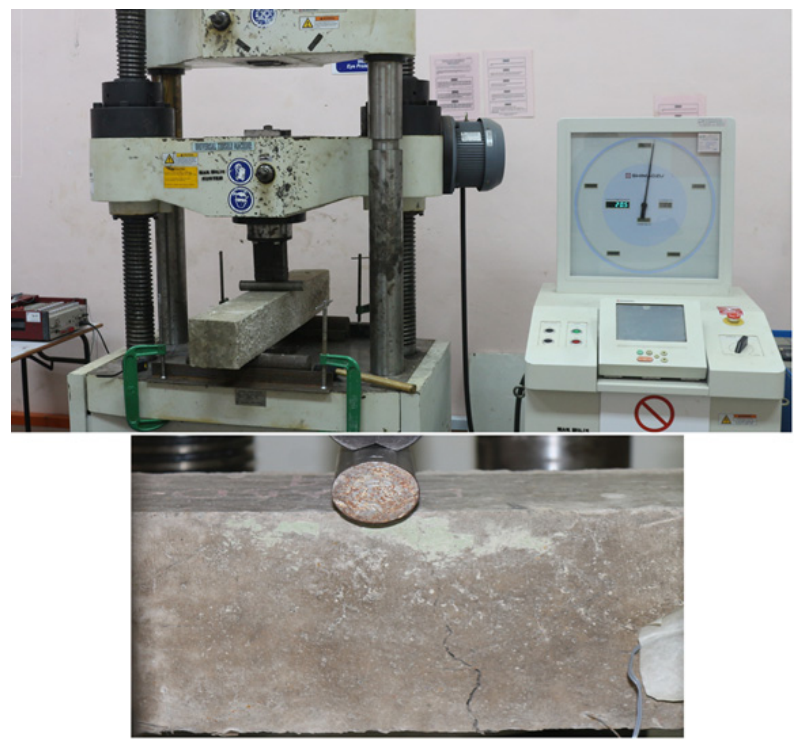

Figure 14: Failure mode for beam B2, non-fiber reinforced concrete.

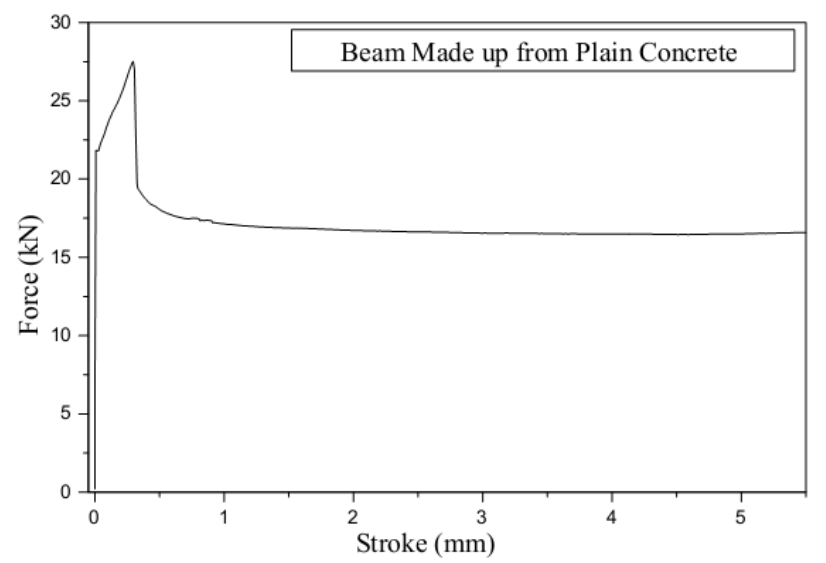

Figure 16: Force vs stroke in beam B2, non-fiber reinforced concrete.

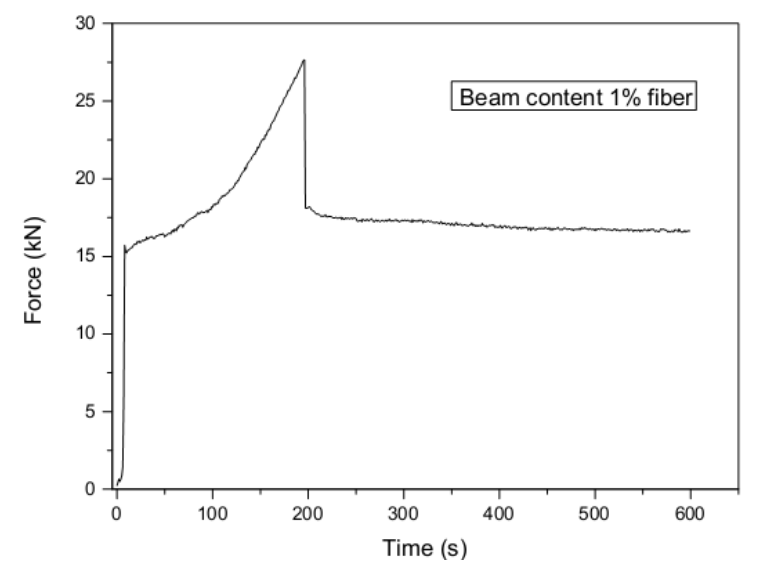

Figure 13: Force vs time in beam B1, content 1\% steel fibers.

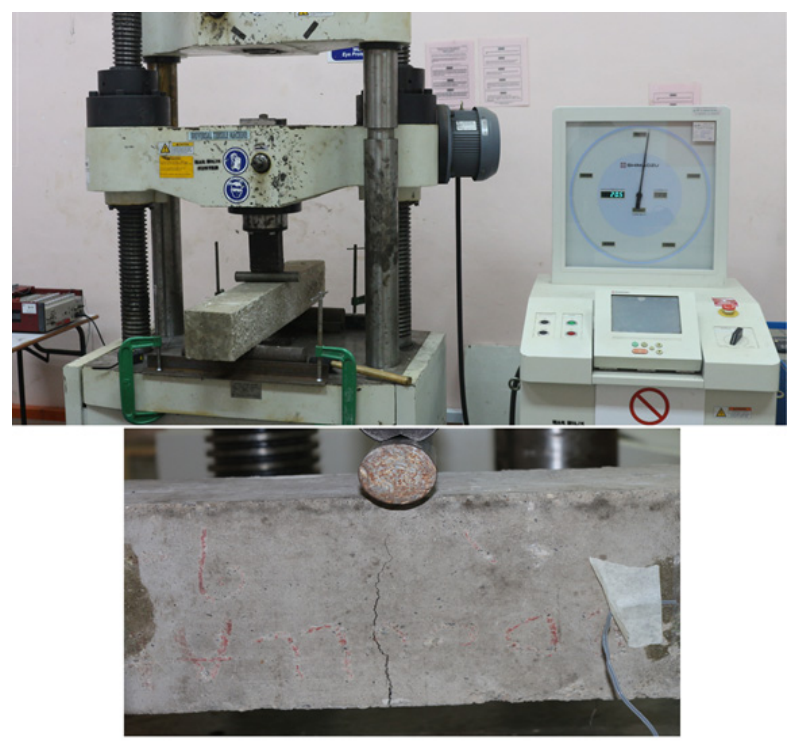

Figure 15: Failure mode for beam B2, content 1.0\% steel fibers. .

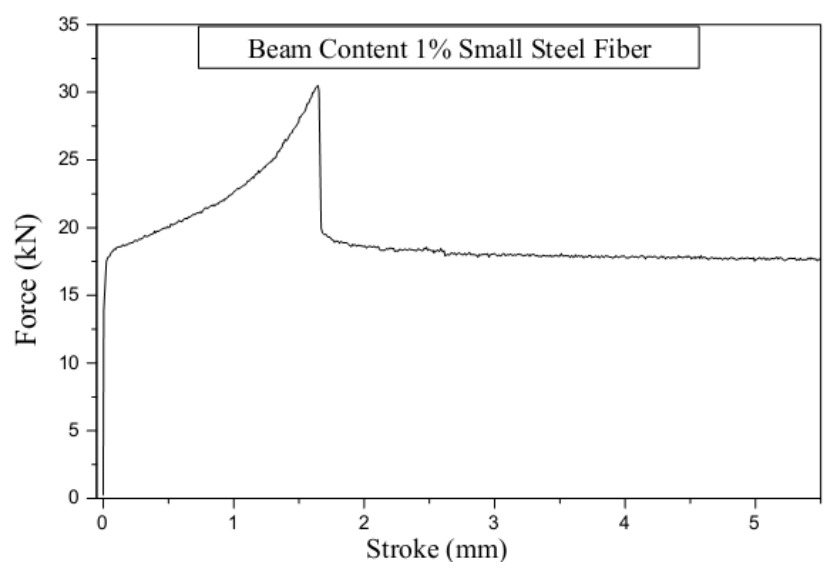

Figure 17: Force vs stroke in beam B2, content 1.0\% steel fibers. 


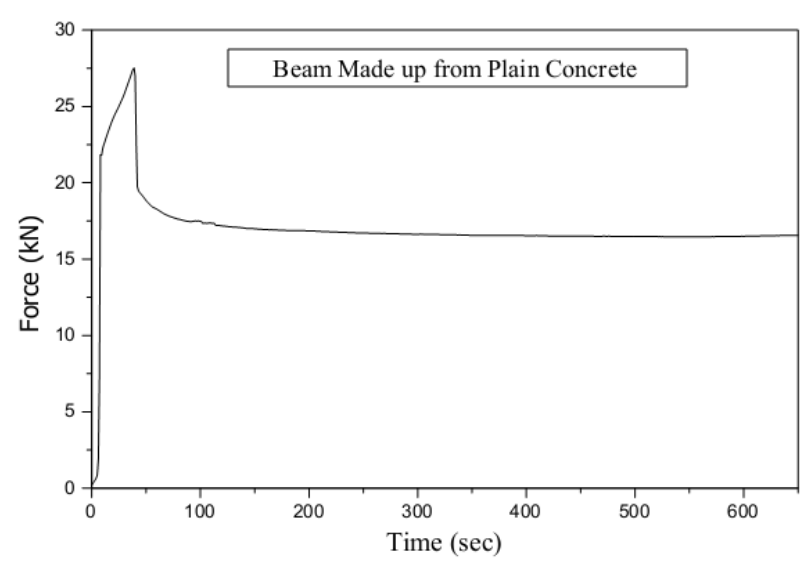

Figure 18: Force vs time in beam B2, non-fiber reinforced concrete.

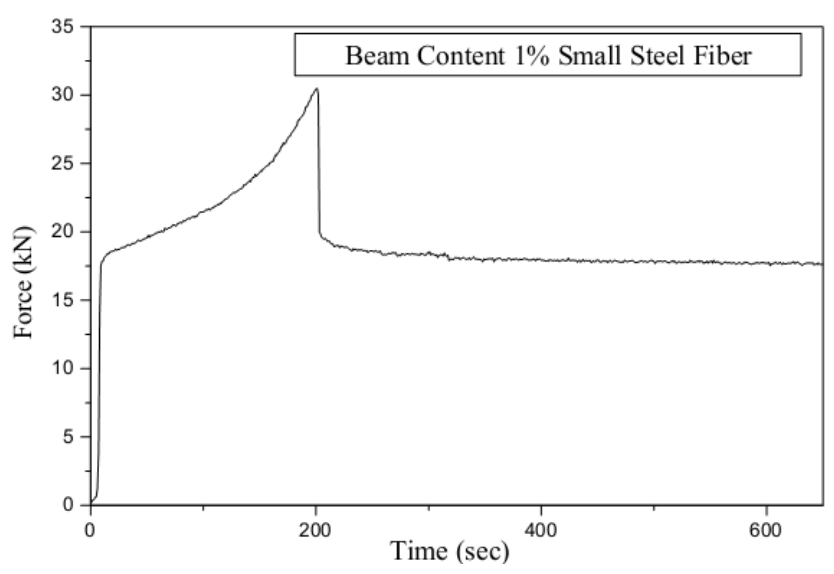

Figure 19: Force vs time in beam B2, content $1.0 \%$ steel fibers.

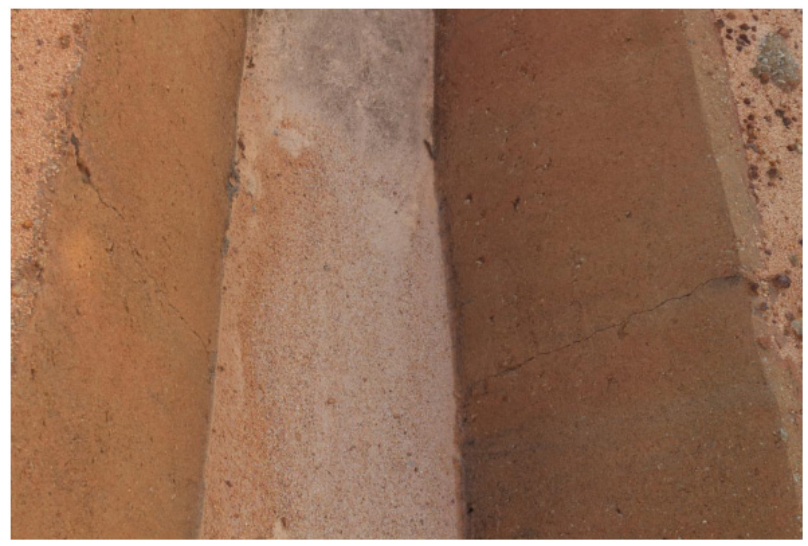

Figure 20: Crack on drainage networks facility, made up from thin plain concrete cross section.

The accumulating sediment inside concrete drainage channel due to erosion, increases surcharge, decreases load acceptability and causes crack on channel (Fig. 20). This problem can be controlled by enhancement of flexural strength of concrete. The reinforced steel cannot use in this thin cross section. By using small steel fiber in concrete mix design, appropriate flexural strength of concrete expects. This method mitigates collapse of concrete channel. The fiber reinforced concrete controls graph of force versus time stability, force versus deflection, morphology of cracks and time of starting cracks. Enhancement of type of steel fiber improves stability of beam. The research program continues on how to improve the flexural strength of concrete beam by using different types and proportion of steel fiber. The shape and length of steel fiber plays important role in this investigation. Graph of force versus time indicates flexibility of beam improves when beam content 1\% steel fiber. According to this research plan the appropriate small steel fiber improves flexural strength of beam and minimizes crack on beam.

\section{CoNClusions}

7 he research outcomes indicate that this method is one of the easiest, cost effective technique and less time consumer for enhancement of flexural strength of concrete beam. In steel-concrete mixture design, different proportion and length of steel fibers have been used. Two types of beams have been investigated. It has been understood that the type of mode failure for concrete beam depends on small steel fiber proportion and distribution. The strain gauges have been installed on beam, to measure level of applied force, deflection and time to failure of beams. The morphology of crack has been studied. Shear crack, flexural crack and intermediate shear-flexural crack have been observed. The steel fiber has been controlled shear crack morphology. Increase quantity of fiber, improves flexural strength of beam. To improve flexural strength of thin cross section concrete the proposed method is well suitable. In this 
research work smooth steel fiber has been used. It is well known that deformed steel fiber and rough surface steel fiber exhibit better performance.

\section{REFERENCES}

[1] Kang, S.T., Lee, B.Y., Kim, J.K., Kim, Y.Y., The effect of fibre distribution characteristics on the flexural strength of steel fibre-reinforced ultra high strength concrete, Construction and Building Materials, 25 (2011) 2450-2457.

[2] Stähli, V., Sutter, M., van Mier, JGM., Improving the mechanical properties of HFC by adjusting the filling method, In: Proceeding of RILEM fifth international workshop on high performance fibre reinforced cement composites (HPFRCC5), Mainz, Germany, (2007) 23-30.

[3] Toutanji, H., Bayasi, Z., Effect of manufacturing techniques on the flexural behaviour of steel fiber-reinforced concrete, Cem Concr Res, 28 (1998) 115-24.

[4] Yang, I.H., Joh, C., Kim, B.S., Flexural strength of ultra high strength concrete beams reinforced with steel fibers, Procedia Engineering, 14 (2011) 793-796.

[5] Deng, J., Lee, M.M.K., Li, S., Flexural strength of steel-concrete composite beams reinforced with a prestressed CFRP plate, Construction and Building Materials, 25 (2011) 379-384.

[6] Khaloo, A.R., Afshari, M., Flexural behaviour of small steel fibre reinforced concrete slabs, Cement \& Concrete Composites, 27 (2005) 141-149.

[7] Ghalib, M.A., Moment capacity of steel fibre reinforced small concrete slabs, ACI Journal, (1980) 247-57

[8] Bernal, S., Gutierrez, R.D., Delvasto, S., Rodriguez, E., Performance of an alkali-activated slag concrete reinforced with steel fibers, Construction and Building Materials, 24 (2010) 208-214.

[9] Soutsos, M.N., Le, T.T., Lampropoulos, A.P., Flexural performance of fibre reinforced concrete made with steel and synthetic fibres, Construction and Building Materials, 36 (2012) 704-710.

\section{NOMENCLATURE}

L.F $=$ Length of fiber $(\mathrm{mm})$

$\mathrm{W} . \mathrm{F}=$ Weight of fiber in a beam $(\mathrm{g})$

$\% . \mathrm{F}=\%$ of fiber in a beam

$\mathrm{B} 1=$ Beam with dimension of $100(\mathrm{~mm}) \times 100(\mathrm{~mm}) \times 500(\mathrm{~mm})$

$\mathrm{B} 2=$ Beam with dimension of $150(\mathrm{~mm}) \times 150(\mathrm{~mm}) \times 1000(\mathrm{~mm})$ 